\title{
Numerical analysis of solar chimney power plant system: Algeria as a case study
}

\author{
RABEHI RAYAN ${ }^{1, a}$, CHAKER ABLA ${ }^{1, b}$, AOUACHRIA ZEROUAL \\ 2 , TINGZHEN MING ${ }^{3}$ \\ ${ }^{1}$ Department of physics, Constantine 1 University, Constantine, Algeria \\ ${ }^{2}$ Department of physics, El Hadj Lakher University, Batna, Algeria \\ ${ }^{3}$ Department of Built Environment and Energy Engineering, Wuhan university of Technology, China \\ aemail: raya.phys@gmail.com, bemail: chakamine@yahoo.fr
}

Keywords: solar, solar chimney, Algeria, numerical simulation, performance

\begin{abstract}
Solar energy holds great significance in the research programs on renewable energy. Recent studies show that with the use of solar energy, we can create a movement of air in the form of artificial wind. This air flow is used to drive one or more wind turbines and produce electrical energy. At this conversion appear thermal and dynamic coupled phenomena. The objective of this work is to simulate these phenomena in the solar chimney to estimate the electrical power produced by the solar chimney power plant as well as to study the effect of different climatic conditions on energy production in some regions of Algeria, using the commercial code Fluent. A solar chimney of $200 \mathrm{~m}$ height and $240 \mathrm{~m}$ collector diameter is capable of producing electrical power from 40 to $70 \mathrm{KW}$ monthly as a yearly average. The results for the regions of Constantine, Ouargla, Adrar and Tamanrasset are consistent with the literature.
\end{abstract}

\section{Introduction}

Algeria has unveiled its development plan for renewable energy, discussions are focusing on the best technological choice for the country, amongst others, we find solar chimney power plants. The collector is open to the periphery for introducing fresh air to be heated by the solar rays, Several experimental studies have also been carried out and many pilot solar chimneys of different sizes have been constructed [1][2].

The first prototype of a solar chimney is built in Manzanares in 1982. Haaf et al [3] have undertaken initial studies of this prototype. Following this series of tests, many studies have been conducted up to day. Our work consists, to a feasibility study of a solar chimney in the south of Algeria, the energy potential was first performed, which will allow us to analyze the energy efficiency of the installation based on settings whatsoever physical, geometric or meteorological.

Chergui et al. [5] showed in a previous study on solar chimney power plants in southern Algeria, the importance of the Adrar region as an attractive source of thermal solar energy. Our work consists, through feasibility study of a solar chimney in southern Algeria, to proceed first to do an energy study, which will allow us to analyze the energy efficiency of the plant based on physical parameters such as, meteorological, geometric, solar radiation, ambient temperature, tower height and collector diameter. An additional study is needed for the sitting of the turbines in the chimney.

\section{Physical and Mathematical Modeling}

\section{Physical model}

In this study, the Spanish prototype shown in Fig. 2 is chosen as the physical model for the numerical simulation. The prototype has a fireplace of $195 \mathrm{~m}$ height and radius of $5 \mathrm{~m}$ and a collector of the radius of $120 \mathrm{~m}$ and $2 \mathrm{~m}$ high. The problem is axisymmetric; the two-dimensional geometry, which corresponds to half of the flow field, is to be treated. The Fluent software defaults to the axis $(\mathrm{Ox})$ as the axis of symmetry; this leads us to adapt the computational domain by 
applying a rotation axis to the chosen field [7]. We have chosen four stations for the measurement of meteorological data, these stations are scattered on the Algerian territory (Constantine, Ouargla, Adrar and Tamanrasset). These sites are very good locations to benefit from advantages of using solar energy and the adoption of its related technologies. Geographical characteristics of these sites are given in Table 1 . In this work, the monthly average daily global solar radiation data on a a horizontal surface (MJ / m2.day) were obtained from databases resulting from national and international projects such as PVGIS which is an example of public domain data source [8] and Metronome [9], Meteotest as a source of business data. The average and standard deviation of speed vary from one period to another or from one place to another. Processing dynamic and thermal fields identified in the selected regions allows us to obtain the temperature difference between the inlet and the outlet of the collector, thus the air flow passing gave us an idea of the electric power that can be generated in each site.

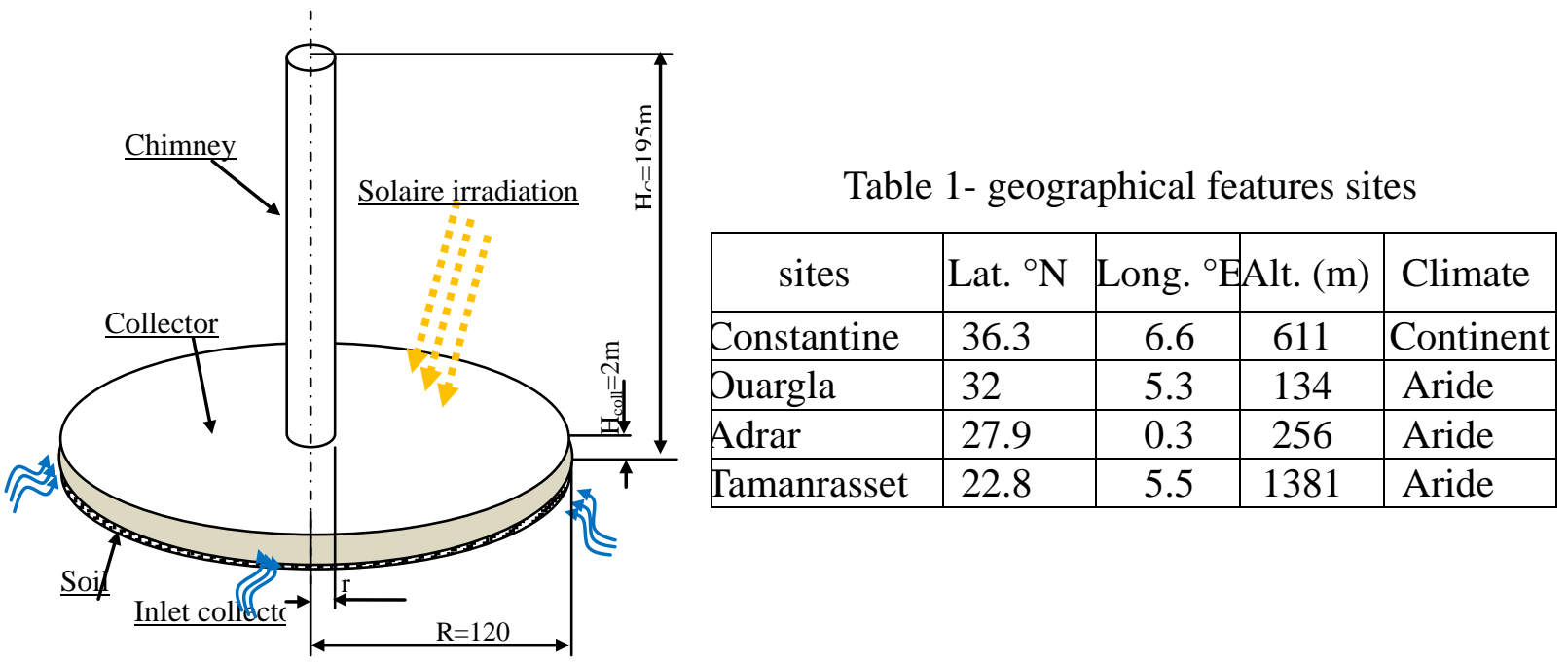

Fig.1: physical presentation and geometrical parameters

\section{Modeling the performance of SCPP}

The performance of the central solar chimney is determined by the performance of its constituent parts.

\section{The collector}

The effectiveness of the collector, with a surface $A_{\text {coll }}=\pi r^{2}$, irradiation $G$ is given by:

$$
\eta_{c o l}=\frac{Q}{\pi r^{2} G}
$$

Where $Q$ is the heat generated by the greenhouse effect in the manifold and is given by:

$$
\begin{aligned}
& Q=C_{p} \cdot m \cdot \Delta T \\
& m=\rho_{\text {air }} \cdot v_{c h} \cdot A_{c h}
\end{aligned}
$$

With

Where $m, A_{c h}$ and $V_{c h}$ is the mass flow, the surface and the velocity at the entrance to the chimney respectively. By replacing in equation (7), $Q$ and $m$ by their expressions, we obtain the relation:

$$
\eta_{c o l}=\frac{\rho_{\text {air }} V_{c h} A_{c h} C_{p} \cdot \Delta T}{\pi r^{2} G}
$$

\section{The chimney}

The effectiveness of the chimney is determined by the following expression: 


$$
\eta_{c h}=\frac{g \cdot H_{c h}}{C_{p} T_{a}}
$$

\section{The turbine model}

The wind turbine, located at the bottom of the chimney, converts the air flow kinetic energy into rotational mechanical energy. According to Ref. [11] the mechanical power absorbed by the turbine is given by:

$$
P_{m}=\frac{2}{3} \eta_{c o l} \eta_{c h} \pi r^{2} G
$$

The efficiency of the turbine usually varies from 0.8 to more than 0.9 for different turbine configurations. [12] The efficiency of the turbine was set at 0.85 to be consistent with other studies in the prediction of the SCPP performance. This assumed value may be a compromise, given the wide variation of operating points and different turbine configurations in practical applications. The electrical power produced for the central solar chimney is given by

$$
P_{e}=\frac{2}{3} \eta_{c o l} \eta_{t} \frac{g}{C_{p} T_{a}} H_{c h} \pi r^{2} G
$$

\section{Study of mass and heat transfer}

\section{Flow Analysis in collector and chimney}

Physical modeling of phenomena related to solar chimneys is complex: it takes into account the heat transfer by conduction, convection and radiation, usually turbulent motion of the air in the collector and the chimney, thermo physical characteristics of the fluid in the study area. Than to obtain the performance of this plant one must determine the mass flow rate and the change in temperature between the manifold inlet and outlet. For this it is necessary to solve the equations governing the flow in the collector and chimney. Generally, if we set the variable $\varphi$, the equations that describe the fluid flow can be reduced by a single equation of convection-diffusion in general form referred to as the transport equation given by the following expression:

$$
\frac{\partial \rho \phi}{\partial t}+\sum_{j} \frac{\partial\left(\rho u_{i} \phi\right)}{\partial x_{i}}=\sum \frac{\partial}{\partial x_{i}}\left(\Gamma_{\phi} \frac{\partial \phi}{\partial x_{i}}\right)+S_{\phi}
$$

The first term of left member represents the temporal variation of the quantity $(\rho \phi)$; the second term is the convective term representing the transport of ${ }^{(\phi)}$ by the momentum flow $\left(\rho u_{i}\right)$. The terms on the right represent the diffusive and source terms. The parameters ${ }^{(\phi)}, \Gamma, S_{\phi}$ are given in Table 2.

The number of cells required to solve a problem depends on the expected accuracy. In order to choose an optimal mesh to obtain acceptable numerical results, we vary the number of cells and monitor the evolution of residues based on the number of iterations. The relative difference between the flow at the inlet and the outlet of the stack is selected as the convergence criterion. Selected residue values are equal to $10^{-3}$ for motion equation of motion, turbulent kinetic energy and turbulent dissipation equation, and both for the continuity equation, whereas the energy equation it is. We also opted for the following operating conditions: Tam $=300 \mathrm{~K}$, Tsoil $=325 \mathrm{~K}, \mathrm{~b}=0.0031 \mathrm{~K}-1$, $\mathrm{r}=1.087 \mathrm{~kg} / \mathrm{m} 3, \mathrm{~m}=1.944 * 10-5 \mathrm{~kg} / \mathrm{s} ; \mathrm{l}=0.0278 \mathrm{~W}, \mathrm{~K}, \mathrm{Cp}=1007.83 \mathrm{~J} / \mathrm{kgK}$. We have chosen four regions, north central and southern Algeria to study the electrical power that can be produced by a unit of electricity production by solar chimney in each of these areas and have idea where this plant is better to be installed. Our interest is primarily focused on these key parameters. Note that the temperature can reach $49^{\circ} \mathrm{C}$ at Adrar in June while in other regions it is between 32 and $37^{\circ} \mathrm{C}$. These maximum values are at $14 \mathrm{~h}$ reach around $15 \mathrm{~h}$ and by region reflecting their thermal inertia. 
Table 2: Values of $\phi, \Gamma$ and $S_{\phi}$ in each equation

\begin{tabular}{|c|c|c|c|}
\hline & $\phi$ & $\Gamma$ & $S_{\phi}$ \\
\hline Continuity equation & 1 & 0 & 0 \\
\hline $\begin{array}{c}\text { X component momentum } \\
\text { equation }\end{array}$ & $\mathrm{U}^{*}$ & $\frac{1}{R e}$ & $-\frac{\partial P}{\partial x^{*}}$ \\
\hline $\begin{array}{c}\text { Y component } \\
\text { momentum equation }\end{array}$ & $\mathrm{V}^{*}$ & $\frac{1}{R e}$ & $-\frac{\partial P}{\partial x^{*}}+\theta$ \\
\hline Energy equation & $\theta$ & $\frac{1}{R e P r}$ & 0 \\
\hline Mass transport equation & $\mathrm{C}^{*}$ & $\frac{1}{\operatorname{ReSC}}$ & 0 \\
\hline
\end{tabular}

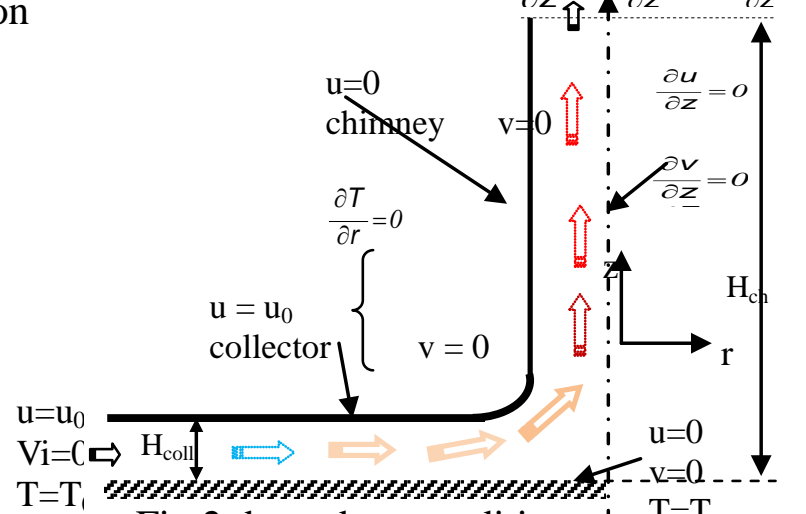

Fig.2: boundary conditions

\section{Results and discussion}

The figure 3 shows the variation of the mass flow at the manifold inlet. From this figure we remark that the mass flow rate increases over time up until reached its maximum value between $12 \mathrm{~h}$ and $14 \mathrm{~h}$ and then it starts to decrease and it justifies the change in the air velocity in the collector. Figure 5 illustrates the temperature difference between the inlet and the outlet of the collector. This temperature difference is increasing over time to a maximum value which is reached at 01:00 pm and then it decreases in all regions. But note that $\Delta \mathrm{T}$ for the Constantine region is higher than other regions contrary to Adrar region. If the ambient temperature is $30^{\circ} \mathrm{C}$ at $01: 00 \mathrm{pm}$ in Constantine and the outlet temperature of the collector is $54^{\circ} \mathrm{C}$ the difference is $24^{\circ} \mathrm{C}$, however for Adrar region, if the ambient temperature is $50{ }^{\circ} \mathrm{C}$ and the temperature at the outlet of the collector is $71^{\circ} \mathrm{C}$, the temperature difference is $21^{\circ} \mathrm{C}$.

The electric power produced each month by a central solar chimney located in the four regions is presented in Figure 3. This figure shows that the region of Tamanrasset has better power generation compared to other regions; it is about $72 \mathrm{KW}$ in June, while production is $68 \mathrm{KW}$ in Constantine in the same month. Figure 6 shows the variation of the electrical power schedule for the month of June, it is remarkable that all the curves of the electric power have a similar shape (bell-shaped) reaching the height between 12, more the solar radiation is higher, power generation is larger. The fact that Constantine sunlight is less, the results show that the same electric power than other regions may be generated, and it refers to the low ambient temperature in Constantine. In Tamanrasset region maximum power is $113 \mathrm{~kW}$ at 12:00 am, while in other regions the power is almost the same, 109 KW.

The numerical simulation is performed by Fluent software (Version 6.2.16) using the finite volume method for the discretisation of general transport equation (8) adopting a structured quadrilateral mesh. It leads to a system of equations, linear and decoupled solved iteratively. All numerical calculations are done in double precision. The iteration error was less than $10^{-3}$ for all calculations, and less than $10^{-6}$ for the energy equation. The comparison our thermal profile with [7] gives a good agreement fig.4.
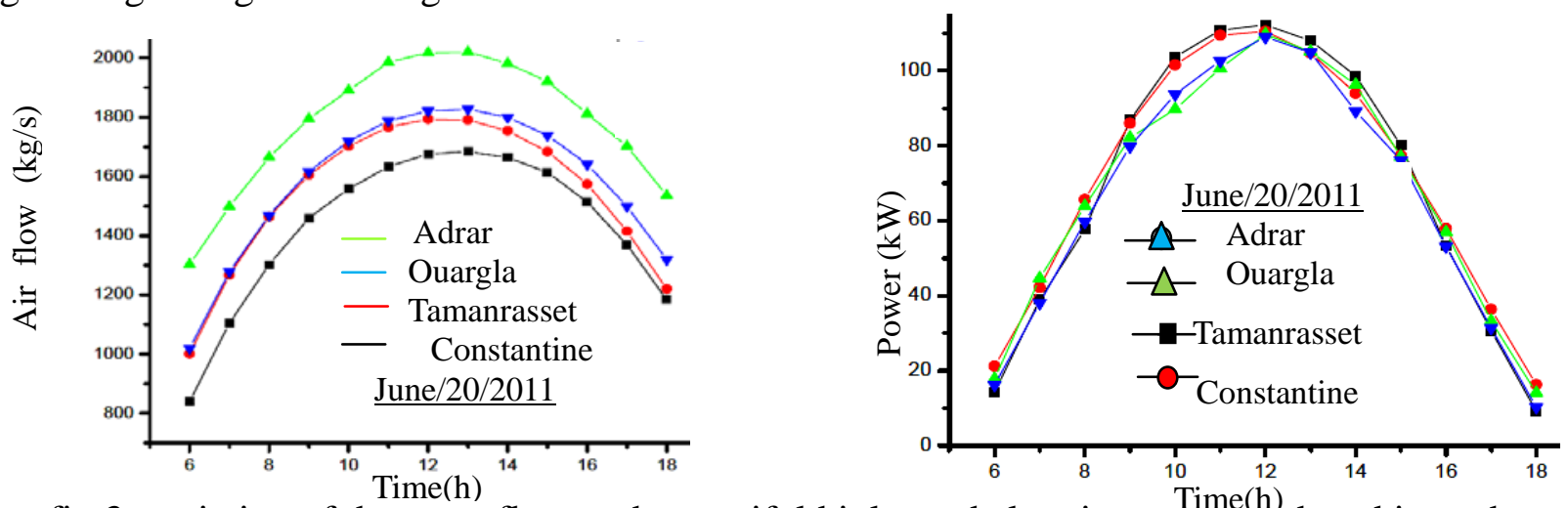

fig.3: variation of the mass flow at the manifold inlet and electric power produced in each station 


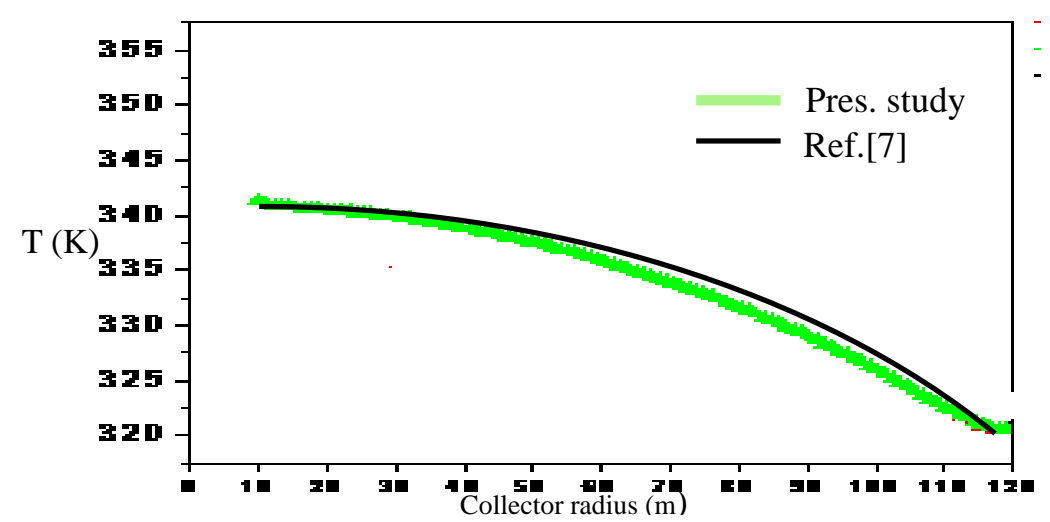

Fig.4: comparison the thermal profile along the manifold between present study and ref. [7]

It is clear that this dynamic field takes a slightly accelerated pace in the manifold inlet and which is amplified gradually in proportion as we approach the location area of wind turbines. One then asserts that this evolution profiles is less nuanced the manifold inlet to its outlet.

Rapid acceleration, generated by the chimney effect is born at different positions of the collector, for different input speeds. One may say that the input speed influences directly on the position where the acceleration begins to grow. Indeed, the point where the acceleration of the air is located at $\mathrm{r}=52.5 \mathrm{~m}$ for $\mathrm{v}=0.5 \mathrm{~m} / \mathrm{s}$ and the speed of $1 \mathrm{~m} / \mathrm{s}$ it is located at $\mathrm{r}=65 \mathrm{~m}$.
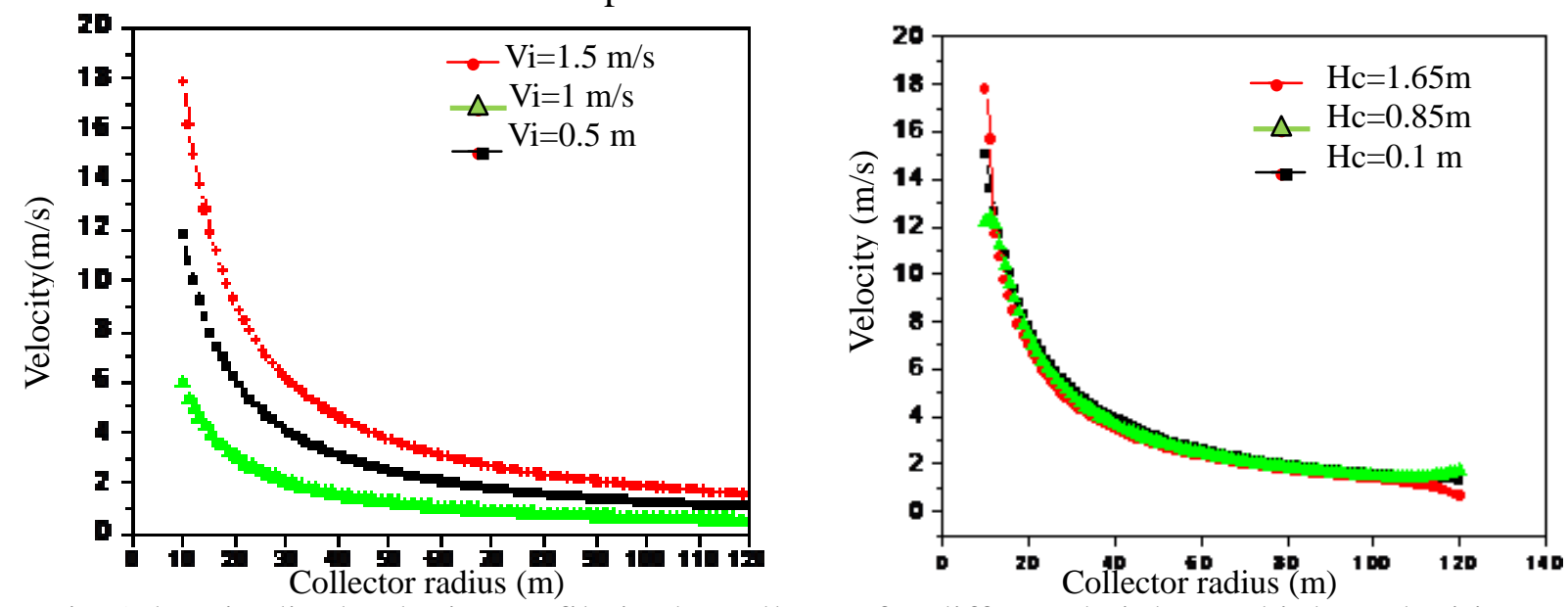

Fig.5: longitudinal velocity profile in the collector for different heights and inlet velocities.

The most interesting effect of the input speed appears at the outlet of the manifold. We note that the increase of the input speed of $0.5 \mathrm{~m} / \mathrm{s}$ generates a neighbouring increase of $8 \mathrm{~m} / \mathrm{s}$. This is very important for the operation of the energy stored in the air masses flowing in the collector. This is beneficial especially for less windy areas as an example, we arrive at the speed of $26 \mathrm{~m} / \mathrm{s}$ for the input speed of $1.5 \mathrm{~m} / \mathrm{s}$, without this system cannot start a wind turbine in this site. Figure 6 shows the evolution of the transverse velocity field in the collector. From these curves the following remarks are drawn: i- The speed variation of the different sections of the collector is performed monotonically. However, this variation is popular near the ground, ii- The speed that prevails in this area is important because of the stack effect which acts to minimize stratification. This effect is highlighted when moving away from the area near the fireplace where stratification is dominant. We note well in the figure; this sudden change may also be due to the edge effect coupled with the stack effect for position 3 at the outlet of the collector. 


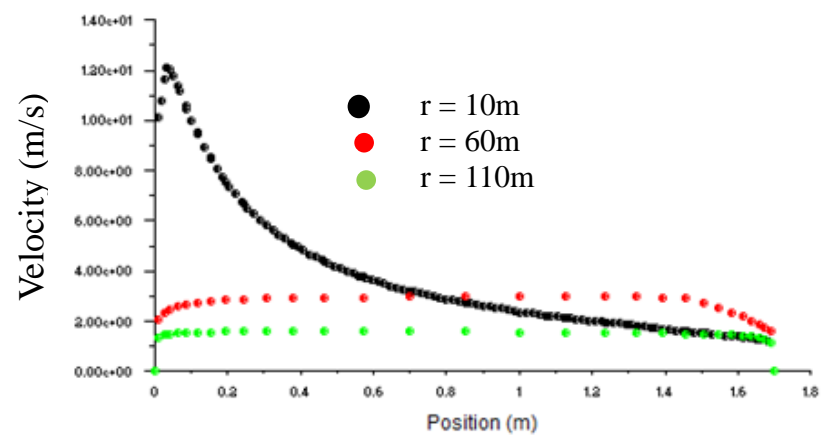

Fig.6: transverse velocity profile for different positions (Adrar area)

\section{Conclusion}

A mathematical model was presented to describe the hydrodynamic and thermal effect in the collector of the solar chimney for the geometry of the Manzanares prototype. From the analyzes performed for four regions: Adrar, Tamanrasset, Ouargla and Constantine we conclude that a solar chimney power plant installed in these areas can produce an average power muzzles between 68 $\mathrm{KW}$ and $72 \mathrm{KW}$. It has been showed that Tamanrasset has better energy production schedule (113 $\mathrm{KW}$ at 12:00 pm) compared with other places, whereas in other studied areas, the power is almost the same $(109 \mathrm{KW})$. We conclude that the adoption of this technology in Algeria is possible and the clean energy produced can meet the needs of the population particularly in southern Algeria.

\section{References}

[1] B. Negrou, H. Belahia, B. Dokkar, M. Drid et N. Settou, Conception d'une turbine éolienne installée dans une cheminée solaire, Revue des Energies Renouvelables CISM’08 Oum El Bouaghi (2008) $265-276$.

[2] J. Schlaich, Tension Structures for Solar Electricity Generation, Engineering Structures Vol. 21, N8, pp. 658 - 668, 1999.

[3] Haaf W. Friedrich, K., and Mayr G., Schailch J.Olar chimneys: part I; principle and construction of the pilot plant in Manzanares. International Journal of Solar Energy 2, (1983), 3-20.

[4] A.J. Gannon T.W.et von Backström, Solar Chimney Cycle Analysis with Loss and Solar Collector Performance, Journal of Solar Energy Engineering, vol1, pp.122-3,(2000).

[5] T. Chergui, S. Larbi, A. Bouhdjar Thermo-hydrodynamic aspect analysis of flows in solar chimney power plants - a case study. Renewable and Sustainable Energy Reviews. (2010).

[6]Salah Larbi, Amor Bouhdjar and Toufik Chergui," Performance analysis of a solar chimney power plant in the southwestern region of Algeria", Renewable and Sustainable Energy Reviews 14, 2010.

[7] R. Rabehi, A. Chaker. Simulation de l'effet hydrodynamique dans une cheminée solaire. 8eme journées tunisiennes sur les écoulements et les transferts. Tunisie 2013.

[8] Meteonorm. Meteonorm Global Metrological Database. http://meteonorm.com/, Accessed 2015.

[9] PVGIS. Système d’information géographique photovoltaïque, http://re.jrc.ec.europa.eu/pvgis.

[10] Roozbeh Sangi, Performance evaluation of solar chimney power plants in Iran, Renewable and sustainable energy reviews 16(2012) 704-710.

[11] Schlaich J., The solar chimney. Stuttgart, Germany: Edition Axel Menges; 1995.

[12] Gannon AJ, von Backström TW. Solar chimney turbine performance. J. Sol. Energy Trans. ASME 2003; 125:101pp. 